\title{
Quantifying water diffusion in high-viscosity and glassy aqueous solutions using a Raman isotope tracer method
}

\author{
H. C. Price ${ }^{1}$, B. J. Murray ${ }^{1}$, J. Mattsson ${ }^{2}$, D. O'Sullivan ${ }^{1}$, T. W. Wilson ${ }^{1}$, K. J. Baustian ${ }^{1}$, and L. G. Benning ${ }^{1}$ \\ ${ }^{1}$ School of Earth and Environment, University of Leeds, Leeds, LS2 9JT, UK \\ ${ }^{2}$ School of Physics and Astronomy, University of Leeds, Leeds, LS2 9JT, UK
}

Correspondence to: H. C. Price (eehcp@leeds.ac.uk) and B. J. Murray (b.j.murray@leeds.ac.uk)

Received: 11 October 2013 - Published in Atmos. Chem. Phys. Discuss.: 8 November 2013

Revised: 13 February 2014 - Accepted: 1 March 2014 - Published: 16 April 2014

\begin{abstract}
Recent research suggests that under certain temperature and relative humidity conditions atmospheric aerosol may be present in the form of a glassy solid. In order to understand the impacts that this may have on aerosolcloud interactions and atmospheric chemistry, knowledge of water diffusion within such aerosol particles is required. Here, a method is described in which Raman spectroscopy is used to observe $\mathrm{D}_{2} \mathrm{O}$ diffusion in high-viscosity aqueous solutions, enabling a quantitative assessment of water diffusion coefficients, $D_{\text {water, }}$, as a function of relative humidity. Results for sucrose solutions compare well with literature data at $23.5 \pm 0.3^{\circ} \mathrm{C}$, and demonstrate that water diffusion is slow $\left(D_{\text {water }} \sim 5 \times 10^{-17} \mathrm{~m}^{2} \mathrm{~s}^{-1}\right)$, but not arrested, just below the glass transition at a water activity of 0.2 . Room temperature water diffusion coefficients are also presented for aqueous levoglucosan and an aqueous mixture of raffinose, dicarboxylic acids and ammonium sulphate: at low humidity, diffusion is retarded but still occurs on millisecond to second timescales in atmospherically relevant-sized particles. The effect of gel formation on diffusion in magnesium sulfate solutions is shown to be markedly different from the gradual decrease in diffusion coefficients of highly viscous liquids. We show that using the Stokes-Einstein equation to determine diffusion timescales from viscosity leads to values which are more than 5 orders of magnitude too big, which emphasises the need to make measurements of diffusion coefficients. In addition, comparison of bounce fraction data for levoglucosan with measured diffusion data reveals that even when particles bounce the diffusion timescales for water are a fraction of a second for a $100 \mathrm{~nm}$ particle. This suggests a high bounce fraction does not necessarily indicate retarded water diffusion.
\end{abstract}

\section{Introduction}

Water-soluble compounds are ubiquitous in atmospheric aerosol, which are important for the planet's climate and hydrological cycle. The ability of aerosol particles to scatter and absorb light impact earth's radiation budget directly, and they also influence climate indirectly by mediating cloud properties through their action as cloud condensation nuclei (CCN) and ice nuclei (IN). It is therefore of vital importance to understand aerosol particle phase transitions and interactions with water vapour, and the consequences of these for aerosol optical properties, chemical reactions and health effects (Pöschl, 2005).

In some aqueous solutions, solute crystallisation at low relative humidity $(\mathrm{RH})$ or temperature can be inhibited, either partially or completely (Prenni et al., 2001; Parsons et al., 2004; Murray, 2008; Murray and Bertram, 2008; Zardini et al., 2008; Bodsworth et al., 2010; Murray et al., 2012). This can be due to an increase in viscosity and associated decrease in the rate of diffusion within the solution as it supersaturates or supercools. A semi-solid state may form, the definition of which often includes ultra-viscous liquids, gels and rubbers (Mikhailov et al., 2009). If the viscosity of the solution increases above $10^{12} \mathrm{~Pa}$ it is said to have formed a glass, or amorphous solid, which may exist out of equilibrium with its surroundings for long timescales (Debenedetti and Stillinger, 2001). It has been proposed that atmospheric aerosol may be present in the form of amorphous solids and semi-solids over a wide range of temperature and relative humidity conditions (Bahreini et al., 2005; Roth et al., 2005; Murray, 2008; Zobrist et al., 2008; Mikhailov et al., 2009; Virtanen et al., 2010; Murray et al., 2012; Perraud et al., 2012; Saukko et al., 2012; Renbaum-Wolff et al., 2013). 
The consequences of the existence of atmospheric aerosol in an ultra-viscous or glassy phase are wide-ranging. Highly viscous aerosol particles have been found to act as heterogeneous IN and may play an important role in cirrus cloud formation (Murray et al., 2010b; Wagner et al., 2012; Wilson et al., 2012; Wang et al., 2012; Baustian et al., 2013). Heterogeneous nucleation of ice on glassy aerosol particles well below water saturation may lead to less, but larger, ice crystals which have a greater sedimentation velocity; this may be particularly important in the very cold and dry topical tropopause region where clouds play a key role in water transport into the stratosphere (Murray et al., 2010b). Reduced diffusion coefficients result in delayed interactions with the gas phase and may impact a particle's optical properties through its ability to take up water (Tong et al., 2011; Bones et al., 2012; Murray et al., 2012). Upon increasing $\mathrm{RH}$, water uptake by amorphous solids occurs at the surface of a particle, proceeding to the interior of the particle only when the outer layer has softened and the rate of diffusion increased (Koop et al., 2011; Zobrist et al., 2011). In this way, the viscosity gradually decreases as the particle undergoes continual deliquescence, and hygroscopic growth occurs at lower relative humidity than for the particle's crystalline counterpart (Mikhailov et al., 2009). When RH is decreased, a core-shell structure may develop as a glassy crust forms around a less viscous interior. In this way water may be trapped inside the particle, even under dry conditions (Koop et al., 2011; Zobrist et al., 2011).

Several studies have suggested that atmospheric aerosol particles are not in equilibrium with surrounding gas phase compounds (Roth et al., 2005; Perraud et al., 2012; Abramson et al., 2013), which may lead to errors in the evaluation of particle-phase and gas-phase concentrations (Liu et al., 2012; Shiraiwa and Seinfeld, 2012; Shiraiwa et al., 2013). The phase of an aerosol particle has been found to affect reactivity (Knopf et al., 2005; Kuwata and Martin, 2012), and the chemical lifetimes of condensed organics can be significantly increased if diffusion is limited (Shiraiwa et al., 2010, 2011; Pfrang et al., 2011). Highly viscous aerosol may undergo diffusion-limited growth, which would result in a different size distribution to that produced by the quasi-equilibrium growth of liquid aerosol (Zhang et al., 2012). In laboratory or field measurements, timescales for equilibration longer than typical thermodenuder residence times may also lead to erroneous volatility results (Saleh et al., 2011), while slow hygroscopic growth may affect hygroscopicity tandem differential mobility analyser (HTDMA) values (Hersey et al., 2013).

Vaden et al. (2011) and Cappa and Wilson (2011) observed slow evaporation rates of secondary organic aerosol (SOA) and attributed this to condensed phase kinetic limitations to gas-particle partitioning. However, slow evaporation would also be seen in particles containing low volatility compounds, such as aged SOA in which low volatility oligomers may form (Cappa and Wilson, 2011; Saleh et al., 2013). In an experiment directly measuring equili- bration timescales at $30^{\circ} \mathrm{C}$, Saleh et al. (2013) reported no substantial gas-particle partitioning inhibition due to kinetic limitations within particles. The discrepancies between evaporation- and equilibration-rate measurements highlight the need for more direct measurements of potential kinetic limitations in aerosol particles.

Current techniques used to determine the formation and properties of semi-solid and glassy aerosol often involve some method of establishing the viscosity, quantitatively or qualitatively (Virtanen et al., 2010; Wang et al., 2012; Renbaum-Wolff et al., 2013). The Stokes-Einstein relation is then sometimes used to estimate the diffusion coefficient. However, there is evidence to suggest that this hydrodynamic description is not generally applicable: the mobility of water and larger molecules deviate near the glass transition (Champion et al., 1997; Rampp et al., 2000; Zhu et al., 2011; Power et al., 2013). In addition, diffusion coefficients do not vary with temperature in the same way as viscosity at $T_{\mathrm{g}} / T>0.8$ (Parker and Ring, 1995). Since it is diffusion, rather than viscosity, which is key to quantifying the response of aerosol to changing conditions, it is advantageous to directly measure the diffusion coefficients of the species of interest, rather than inferring them from the viscosity.

The diffusion coefficient of water, $D_{\text {water }}$, in atmospheric aerosol is an important parameter because water is often the most mobile component of a glassy aqueous solution (Roberts and Debenedetti, 1999), it is crucial in cloud formation processes, and it can act as a plasticiser (Zobrist et al., 2011; Koop et al., 2011). The uncertainty in the current best estimate of $D_{\text {water }}$ in $\alpha$-pinene SOA spans 4 orders of magnitude at RHs below $80 \%$ (Shiraiwa et al., 2013). Furthermore, the plasticising effect of water leads to considerable difficulties in measuring the diffusion coefficient of water in glassy aerosol undergoing hygroscopic growth or shrinkage because the diffusion equation becomes non-linear (Tong et al., 2011). Zobrist et al. (2011) used a model to overcome the issue of non-linearity, and were successful in determining diffusion coefficients from water uptake on aqueous sucrose particles with electrodynamic balance and optical techniques.

We have used a similar technique to Zhu et al. (2011) to determine the diffusion coefficient of water in aqueous solutions. Zhu et al. (2011) brought a $\mathrm{H}_{2} \mathrm{O}$-maltose and a $\mathrm{D}_{2} \mathrm{O}$ maltose droplet together until they touched, and used a Raman microscope to quantify diffusion between the droplets. Our approach relies upon the observation of the diffusion of a gas phase isotope tracer into a disk of aqueous solution. This involves equilibrating the solution at a chosen $\mathrm{RH}$ in $\mathrm{H}_{2} \mathrm{O}$ vapour and then switching to $\mathrm{D}_{2} \mathrm{O}$ vapour of almost the same $\mathrm{RH}$. The progression of $\mathrm{D}_{2} \mathrm{O}$ into the solution disk is then monitored as a function of time and distance which allows a quantitative assessment of the diffusion coefficient. The advantage over techniques which involve changing RH in a stepwise fashion is that the solution to the diffusion equation is greatly simplified since the water content $\left(\mathrm{D}_{2} \mathrm{O}+\mathrm{H}_{2} \mathrm{O}\right)$ of 
the disk remains constant throughout the experiment - there is no radial solute concentration gradient.

The kinetics of water transport in amorphous inorganic aerosol have previously been investigated by Li et al. (2011), who used Raman spectroscopy to observe the exchange of deuterium with hydrogen, but did not determine diffusion coefficients. Ahlqvist and Taylor (2002) also used H/D exchange to observe diffusion in crystalline and amorphous sugars. The method outlined here allows for the quantitative determination of the diffusion coefficient of water in aqueous solutions relevant to atmospheric aerosol over a wide range of RH and temperature conditions, assuming Fickian diffusion. Here, sucrose is studied to allow direct comparison with literature data for method validation. Measurements are then extended to (i) levoglucosan (a major component of biomass burning aerosol, Decesari et al., 2006), (ii) raffinose/M5AS (a mixture of raffinose, dicarboxylic acids and ammonium sulfate, Zobrist et al., 2008) and (iii) magnesium sulfate (present in seawater aerosol and known to have the interesting property of gel formation at low RH; Zhao et al., 2006).

\section{Experimental methods}

\subsection{Raman microscopy}

A Renishaw InVia Raman spectrometer with a $514 \mathrm{~nm}$ laser and motorised XYZ stage was coupled to a temperature and relative humidity controlled chamber (Fig. 1). A dry zero grade $\mathrm{N}_{2}$ flow was humidified as it passed through an $\mathrm{H}_{2} \mathrm{O}$ or $\mathrm{D}_{2} \mathrm{O}$ bubbler, whose temperature was regulated by a chiller, and then diluted to the desired dew point with additional $\mathrm{N}_{2}$. The dew point of the outflow from the chamber was recorded using a GE Optica hygrometer with model 1311DR sensor. The stage temperature was maintained at $23.5 \pm 0.3{ }^{\circ} \mathrm{C}$ using a separate recirculating chiller and measured using a PT100 platinum resistance thermometer. This temperature was chosen for the present study to facilitate comparison with literature data and to reduce experimental duration; experiments at lower temperatures will be the subject of future work. Spectra containing information on the chemical composition of the sample could be continually acquired at predetermined locations on the sample with a laser spot size of $1.3 \mu \mathrm{m}$. A 600 lines $\mathrm{mm}^{-1}$ grating was used, enabling Raman intensities to be simultaneously collected across the wavenumber range of interest. All spectral and environmental data were computer-logged for subsequent analysis.

\subsection{Diffusion in a disk}

The two separate locations of the O-H and the O-D bond stretch bands in the Raman spectrum were used to monitor the diffusion of $\mathrm{D}_{2} \mathrm{O}$ from the gas phase into a $\mathrm{H}_{2} \mathrm{O}$ solution droplet. In order to avoid inhomogeneity in the vertical column of sample which contributed to the Raman signal, a disk of solution was prepared such that its circumference (but neither face) was exposed to the surrounding gases (Fig. 2a). In this way, diffusion only occurred horizontally in the radial direction.

Assuming that a disk is homogenous (i.e. the diffusion coefficient does not depend on radial position) Fick's second law is

$$
\frac{\partial \varphi(r, t)}{\partial t}=D \nabla^{2} \varphi(r, t),
$$

where $\varphi$ is the concentration of the diffusing molecule in mol m $\mathrm{m}^{-3}, t$ is time and $D$ is the diffusion coefficient in $\mathrm{m}^{2} \mathrm{~s}^{-1}$. A solution to the above equation for a disk of radius $a$ whose edge is maintained at concentration $\varphi_{0}$ is

$$
\varphi(r, t)=\varphi_{0}+2\left(\varphi_{1}-\varphi_{0}\right) \sum_{\alpha} \frac{1}{\alpha J_{1}(\alpha)} e^{\frac{-\alpha^{2} D t}{a^{2}}} J_{0}\left(\frac{\alpha r}{a}\right),
$$

where $\varphi_{1}$ is the concentration at $t=0$ everywhere in the disk except at the edge $(r=a)$ at $t=0, J_{0}$ and $J_{1}$ are Bessel's functions of order 0 and 1 , respectively, and $\alpha$ are the positive roots of the equation $J_{0}(x)=0$ (Bowman, 1958).

\section{$2.3 \quad \mathrm{D}_{2} \mathrm{O}$ diffusion measurements}

Dilute aqueous solutions were prepared with pure water (Milli-Q 18.2 M $\Omega \mathrm{cm}$ ). The solutes used were sucrose (Sigma, > 99.5\%), levoglucosan (Acros Organics, > $99 \%$ ), magnesium sulfate (Sigma-Aldrich, $>99.5 \%$ ) and raffinose/M5AS (50 wt \% D-(+)-raffinose pentahydrate (Alfa Aesar, > 99\%), $15.4 \mathrm{wt} \%$ malonic acid (Alfa Aesar, > $99 \%$ ), $7.1 \%$ maleic acid (Fluka, >99\%), 7.4\% DL-malic acid (Aldrich, >99\%), $3.7 \%$ methylsuccinic acid (Aldrich, $>99 \%$ ), $8.9 \%$ glutaric acid (Alfa Aesar, > $99 \%$ ) and $7.7 \%$ ammonium sulfate (Fluka, $>99.5 \%$ ). For each experiment, a $\sim 0.5 \mu \mathrm{L}$ droplet of solution was placed on a hydrophobic siliconised glass slide (Hampton Research) using a micropipette and allowed to adapt its size as it equilibrated with the surrounding air. Similarly coated glass slides have been used previously and shown not to trigger nucleation (Murray et al., 2010a, 2011, 2012; Broadley et al., 2012; Atkinson et al., 2013). A smaller piece of hydrophobic glass was placed on top of the droplet, supported by a pair of $25 \mu \mathrm{m}$-thick Teflon film spacers, in order to create a disk of $200-300 \mu \mathrm{m}$ radius (Fig. 2a). The slide was then placed in a temperature and humidity controlled chamber, initially at $90 \% \mathrm{RH}$.

For each experiment, the solution disk was exposed to a flow of nitrogen gas with a controlled partial pressure of $\mathrm{H}_{2} \mathrm{O}$ vapour in order to achieve the water activity corresponding to the chosen RH. In these experiments it was essential that the water activity across the disk was constant, so it was important that the disk was exposed to $\mathrm{H}_{2} \mathrm{O}$ vapour for a sufficient period of time. This time required for equilibration depended on solute and $\mathrm{RH}$; the lower the $\mathrm{RH}$, the longer the $\mathrm{H}_{2} \mathrm{O}$ equilibration time. Hence, it was necessary to estimate 


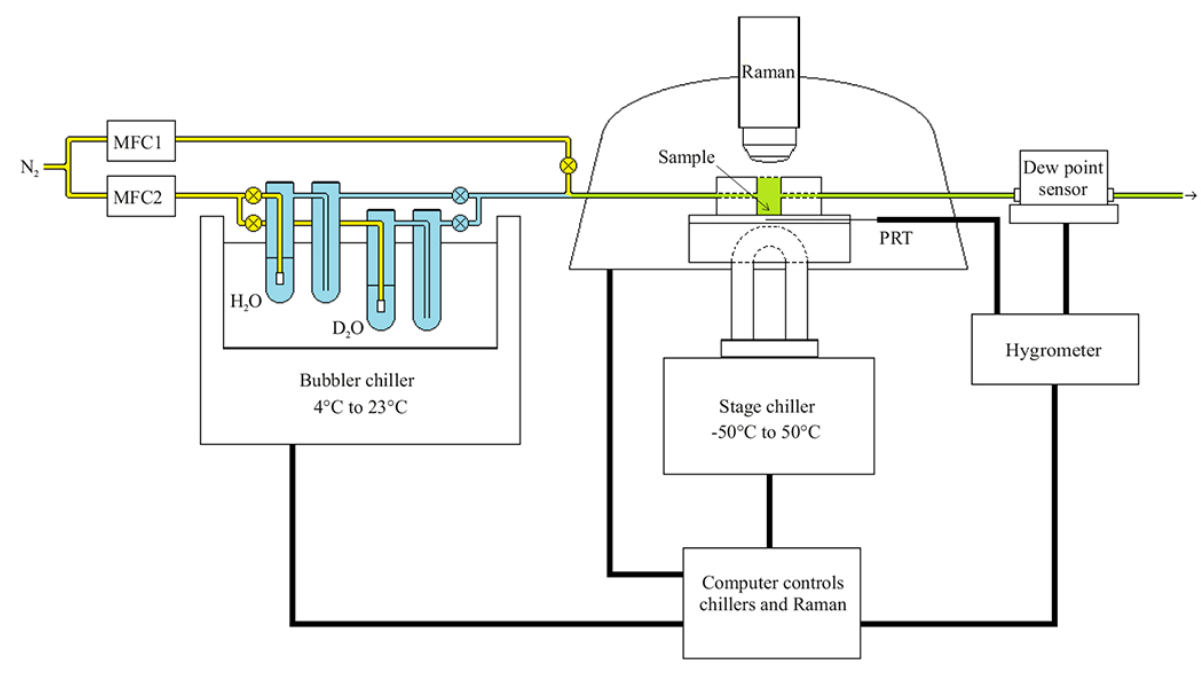

Fig. 1. Humidity and temperature controlled Raman spectroscopy setup. Nitrogen gas flows were regulated using two mass flow controllers (MFC1 and MFC2) and either remained dry or were humidified in a bubbler. The two flows were mixed at a known ratio to produce the desired relative humidity at the stage, which was also temperature controlled. A hygrometer logged temperature and humidity data.

(a)

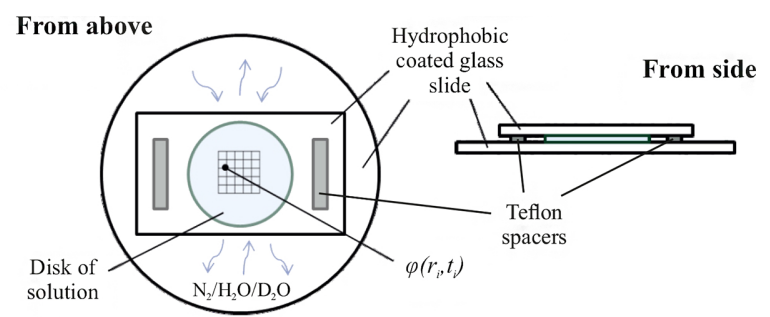

(b)

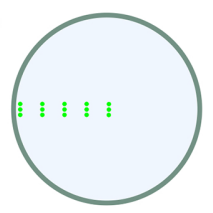

(c)

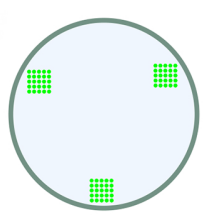

Fig. 2. (a) Arrangement of a disk on the slide in the $\mathrm{D}_{2} \mathrm{O}$ diffusion experiment. The slide was placed in the $\mathrm{RH}$ and temperature controlled chamber. A typical disk of solution had a size of around $200-300 \mu \mathrm{m}$, and the laser spot had a size of $1.3 \mu \mathrm{m}$. The $25 \mu \mathrm{m}-$ thick spacers and top slide were held in place using vacuum grease. Each Raman spectrum was obtained at a predetermined location on a grid, whose size and spacing was chosen to suit the rate of diffusion in each experiment. Other spacer thicknesses were tested to ensure that results were the same and there were no edge effects. (b) Spectral collection configuration for diffusion measurements at high RH. (c) Spectral collection configuration for diffusion measurements at low RH.

the diffusion coefficient and solute concentrations at a particular water activity so that the time required for equilibration could be estimated using the solution to Fick's second law for a cylindrical geometry (Eq. 2). In this case, $\varphi_{0}$ was the water concentration corresponding to the target water activity,

and $\varphi_{1}$ was the water concentration corresponding to a water activity of 0.9 (i.e. the concentration at the start, defined by the starting RH of $90 \%$ ). Water concentrations were calculated using relations between water activity and solute mass fraction given in the literature (Ha and Chan, 1999; Zobrist et al., 2011; Lienhard et al., 2012; Wagner et al., 2012), and densities estimated assuming the volume additivity of pure component densities (Tong et al., 2011). The diffusion coefficient used in this estimation was a best initial estimate of the diffusion coefficient of water in the disk at the target water activity, either taken from the literature or based on the trends of previous measurements. By solving Eq. (2) with these conditions, the time after which the water mass fraction in the centre of the disk corresponded to a water activity within 0.01 of the target water activity could be determined this was used to define the $\mathrm{H}_{2} \mathrm{O}$ exposure time. This process sometimes required several iterations: if the final measured diffusion coefficient was found to be lower than that used in the calculation, the experiment was repeated, this time leaving the disk exposed to $\mathrm{H}_{2} \mathrm{O}$ for a longer time period. The equilibration time varied between minutes at high humidity to weeks at low humidity. In Sect. 3.1 we show that the measured diffusion coefficients are in good agreement with literature data.

In most experiments, equilibration was done at $23.5^{\circ} \mathrm{C}$, but for low water activity experiments which would require impractical $\mathrm{H}_{2} \mathrm{O}$ exposure times at $23.5^{\circ} \mathrm{C}$, the sample was heated to between 40 and $50^{\circ} \mathrm{C}$ to speed up diffusion. Once the necessary exposure time at this temperature had elapsed, the sample was cooled back to $23.5^{\circ} \mathrm{C}$ over a period of several hours, with the RH (and thus water activity) kept constant to within $1 \% \mathrm{RH}$. Any uncertainty in water activity associated with this procedure was accounted for in error bars. 
To confirm that this treatment did not alter the diffusion properties of the sample, two measurements of the water diffusion coefficient in sucrose were made at around $80 \% \mathrm{RH}$, one before exposure to higher temperatures and one after a week at $50^{\circ} \mathrm{C}$. They were in good agreement (see Sect. 3.1).

To determine disk size and location on the motorised XYZ stage, the positions of three points on the disk's circumference were found. This was done by taking three series of spectra along radial tracks traversing the edge of the particle, with $1 \mu \mathrm{m}$ spacing between each spectrum and a laser spot size of $1.3 \mu \mathrm{m}$. For each of these three spectral series, the points at which peaks originating from the sample first appear in the spectra were used to calculate an upper limit on the disk's radius. Similarly, the three points at which the sample peaks reach their maximum intensity were used to determine a lower limit on the disk's radius. The difference between these upper and lower limits was typically around $20 \mu \mathrm{m}$. The best estimate for the disk radius was taken to be the mid-point between the upper and lower limits.

Once the water activity of the disk was estimated to be within 0.01 of $\mathrm{RH} / 100$, the $\mathrm{H}_{2} \mathrm{O}$ vapour was replaced with a flow of $\mathrm{D}_{2} \mathrm{O}$ vapour of the same dew-point. Due to the lower saturation vapour pressure of $\mathrm{D}_{2} \mathrm{O}$, this led to a decrease in RH of up to $1.25 \%$ (Matsunaga and Nagashima, 1987). We estimate that the complete exchange of gases in the pipework and chamber around the solution disk takes $12 \pm 2 \mathrm{~s}$, although in a worst-case scenario where the $\mathrm{D}_{2} \mathrm{O}$ and $\mathrm{H}_{2} \mathrm{O}$ vapours mix only via gas-phase diffusion in the $\mathrm{RH}$-controlled chamber this exchange may take up to $95 \mathrm{~s}$.

The spectrometer was configured to collect Raman spectra after chosen time intervals at locations across a grid covering a portion of the sample disk (see Fig. 2). The spatial and temporal separations of the spectra were chosen such that, as far as possible, a broad range of $\mathrm{D}_{2} \mathrm{O}$ concentrations could be observed over the entire disk radius during the experiment. Each spectrum was measured at a new XY coordinate (and hence radial position), chosen according to the rate of diffusion in each experiment. The $\mathrm{D}_{2} \mathrm{O}$ exposure time required to collect enough information to determine a diffusion coefficient was about $10 \mathrm{~min}$ for a $D_{\text {water }}$ of $10^{-10} \mathrm{~m}^{2} \mathrm{~s}^{-1}$, about $2 \mathrm{~h}$ for a $D_{\text {water }}$ of $10^{-12} \mathrm{~m}^{2} \mathrm{~s}^{-1}$, about $20 \mathrm{~h}$ for a $D_{\text {water }}$ of $10^{-14} \mathrm{~m}^{2} \mathrm{~s}^{-1}$, and about 8 days for a $D_{\text {water }}$ of $10^{-16} \mathrm{~m}^{2} \mathrm{~s}^{-1}$.

The Raman software could be used to define a rectangular grid across which spectra could be collected in a raster fashion. At high diffusion coefficients, it was important to collect data across the entire radius of the disk in a short space of time. For this reason, a grid such as that shown in Fig. $2 b$ was configured, with a $25 \mu \mathrm{m}$ spacing in the $x$ direction and a small (up to $5 \mu \mathrm{m}$ ) spacing in the $y$ direction. Limitations existed at low RH because diffusion was so slow as to make it impractical to wait for high $\mathrm{D}_{2} \mathrm{O}$ concentrations at the disk centre; it was nevertheless possible to determine diffusion coefficients using the concentration measurements near the edge of the disk (see Fig. 2c). At these slow diffusion coefficients, where many spectra could be collected without the concentration gradient changing significantly, it was less important to cover the entire radius of the disk in a short space of time. This allowed us to collect clusters of more spectra at higher spatial resolution (typically with $X$ and $Y$ spacing of $5 \mu \mathrm{m}$ ), with time breaks between each cluster (Fig. 2c). As diffusion progressed, and the O-D band was visible across greater proportions of the radius, the size and number of spectra in each cluster was increased to cover more of the radius.

The time taken to collect each spectrum was typically $1 \mathrm{~s}$, with a further $1 \mathrm{~s}$ period required between spectra for the motorised XYZ stage to move to the next location. This therefore defined the upper limit to the diffusion coefficients which could be measured where diffusion occurred on a minute timescale. Some spectra were longer in duration (up to $40 \mathrm{~s}$ per spectrum) - these longer acquisitions were used where the extra duration did not compromise the time resolution but did improve the quality of the spectral data. For very slow experiments (e.g. sucrose $20 \% \mathrm{RH}$, which involved a 3 -week $\mathrm{D}_{2} \mathrm{O}$ exposure), there were breaks between several series of spectral acquisitions in order to avoid wear on the laser.

The number of points used in each surface fit varied according to the duration of each experiment, which was directly influenced by the rate of diffusion at each relative humidity. Experiments where diffusion coefficients were large typically involved the collection of several hundred spectra (and thus data points in the surface fit); experiments with the smallest diffusion coefficients usually generated several thousand spectra.

After the exchange had taken place, the process of determining the disk radius by finding the positions of three points on the disk edge was repeated. Decreases in radius of up to $3 \%$ were noted; this can be accounted for by the combined effects of a change in volume due to isotope exchange (Bartell and Roskos, 1966), and a change in water activity due to the lower saturation vapour pressure of $\mathrm{D}_{2} \mathrm{O}$ (Matsunaga and Nagashima, 1987). The shrinkage was included in the calculation of the error bars associated with each data point.

Raffinose/M5AS was seen to fluoresce at the lowest water activity investigated (0.22), which meant the Raman scattering bands were partially obscured (no significant fluorescence was observed at other humidities or in the other samples). To minimise these effects, the Raman laser was used to photobleach the sample for $500 \mathrm{~s}$ prior to each spectral acquisition. Since any photobleaching-induced effects would have been concentrated in a small area due to the small laser spot size, and given that each spectrum was acquired in a new position, we do not expect any effects on the determined diffusion properties from the bleaching technique. 


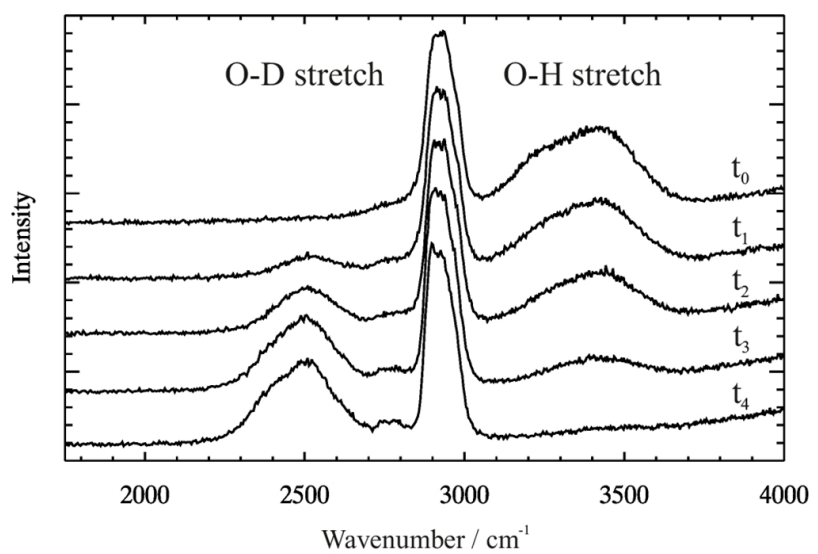

Fig. 3. Raw Raman data showing the gradual decrease in the O$\mathrm{H}$ stretch (at 3100 to $3500 \mathrm{~cm}^{-1}$ ) band and increase in the O-D stretch (at 2300 to $2700 \mathrm{~cm}^{-1}$ ) band after switching from $\mathrm{H}_{2} \mathrm{O}$ to $\mathrm{D}_{2} \mathrm{O}$ vapour. The central band (at 2800 to $3100 \mathrm{~cm}^{-1}$ ) is the $\mathrm{C}-\mathrm{H}$ stretch.

\subsection{Analysis of Raman data to determine diffusion coefficients}

The Raman spectra of aqueous solutions of organics such as sucrose and levoglucosan are characterised at high wavenumbers by $\mathrm{C}-\mathrm{H}$ stretch bands at $\sim 2800$ to $3100 \mathrm{~cm}^{-1}$ and $\mathrm{O}-$ $\mathrm{H}$ stretch bands at $\sim 3100$ to $3500 \mathrm{~cm}^{-1}$. The $\mathrm{C}-\mathrm{H}$ stretch band originates entirely from the organic molecules, whilst the $\mathrm{O}-\mathrm{H}$ band originates from hydroxyl groups both in the organic and in water. The magnesium sulfate spectrum lacks the $\mathrm{C}-\mathrm{H}$ stretch, whilst the raffinose/M5AS spectrum also features a band arising from the $\mathrm{NH}_{4}^{+}$species which is situated around $3100 \mathrm{~cm}^{-1}$. This band was small (due to the relatively small amount of ammonium in the mixture) and overlapped with the O-H stretch. The O-D stretch band is located at $\sim 2500 \mathrm{~cm}^{-1}$, which is $\frac{1}{\sqrt{2}}$ times the $\mathrm{O}-\mathrm{H}$ stretch frequency, and has a lower integrated intensity than the $\mathrm{O}-\mathrm{H}$ stretch band by a factor of $\frac{1}{\sqrt{2}}$ (Kohen and Limbach, 2010). Similarly, the $\mathrm{ND}_{4}^{+}$band is located at $\sim 2200 \mathrm{~cm}^{-1}$. After switching from $\mathrm{H}_{2} \mathrm{O}$ vapour to $\mathrm{D}_{2} \mathrm{O}$ flow, the $\mathrm{O}-\mathrm{H}$ stretch band decreased in area, whilst the O-D band appeared and grew (Fig. 3). In raffinose/M5AS, the $\mathrm{NH}_{4}^{+}$band was also seen to decrease whilst the $\mathrm{ND}_{4}^{+}$band grew. The area of the $\mathrm{C}-\mathrm{H}$ stretch band did not decrease: hydrogen atoms on oxygen or nitrogen may exchange with deuterium due to the polarisation of the electron density within the bond, whilst $\mathrm{C}-\mathrm{H}$ bonds do not exchange as they are not sufficiently polarised.

Using the Levenberg-Marquardt technique (Markwardt, 2008), a set of Gaussian peaks were fitted to the spectral bands (Fig. 4). The background was accounted for using a constant plus a broad, high-frequency Gaussian which smoothly matched the low- and high-frequency ends of the spectra. It should be emphasised that the spectral fits produced here are not intended as accurate band assignments.
The sole purpose is to achieve a reasonable, backgroundcorrected quantification of the relative integrated band intensities of the broad O-H and O-D bands.

For sucrose, levoglucosan and raffinose/M5AS, the parameters describing these Gaussian functions (i.e. peak height, width and wavenumber) were constrained so that variable intensity peaks were fitted to the $\mathrm{O}-\mathrm{H}, \mathrm{NH}_{4}^{+}$, O-D and $\mathrm{ND}_{4}^{+}$ bands, and fixed intensity peaks were fitted to the $\mathrm{C}-\mathrm{H}$ band. A satisfactory fit with a reduced $\chi^{2}$ value close to 1 was achieved by fitting up to three Gaussians to the $\mathrm{O}-\mathrm{H}$ band (or the combined $\mathrm{O}-\mathrm{H}$ and $\mathrm{NH}_{4}^{+}$bands in the case of raffinose/M5AS), up to three Gaussians to the O-D band (or the combined O-D and $\mathrm{ND}_{4}^{+}$bands in the case of raffinose/M5AS), and up to five Gaussians to the $\mathrm{C}-\mathrm{H}$ band. Constraining the parameters describing these peaks was particularly important in the overlap region between the O-D and $\mathrm{C}-\mathrm{H}$ bands. So that no C-H intensity was attributed to O-D vibrations, the $\mathrm{C}-\mathrm{H}$ stretch bands were initially fitted before any $\mathrm{D}_{2} \mathrm{O}$ exposure. As the $\mathrm{C}-\mathrm{H}$ band would not vary during the experiment, the parameters found in this initial fit to the corresponding Gaussian peaks were used to constrain the C$\mathrm{H}$ band fit when $\mathrm{D}_{2} \mathrm{O}$ was present. For magnesium sulfate (Fig. 4d), up to four Gaussians were fitted to the O-H stretch and up to four to the O-D stretch, as well as a weak Gaussian to account for a slightly raised background at $\sim 2450 \mathrm{~cm}^{-1}$.

The results of the spectral fitting procedure were used with Eq. (2) to find the diffusion coefficient of $\mathrm{D}_{2} \mathrm{O}$ in the sample. Unlike in Sect. 2.3, $\varphi$ is now the $\mathrm{D}_{2} \mathrm{O}$ concentration. Because the total amount of water $\left(\mathrm{D}_{2} \mathrm{O}\right.$ plus $\left.\mathrm{H}_{2} \mathrm{O}\right)$ and solute remain constant throughout the experiment, $\varphi$ can simply be written as the fractional concentration of O-D bonds relative to the total O-D and O-H bonds at each spectral location and time. Thus,

$\varphi=\frac{A_{\mathrm{OD}}}{A_{\mathrm{OD}}+\frac{1}{\sqrt{2}} A_{\mathrm{OH}}}$,

where $A_{\mathrm{OD}}$ is the integrated intensity of the O-D stretch (i.e. the summed areas of the Gaussian curves representing the broad band between $2300 \mathrm{~cm}^{-1}$ and $2700 \mathrm{~cm}^{-1}$ ) and $A_{\mathrm{OH}}$ is the integrated intensity of the $\mathrm{O}-\mathrm{H}$ stretch (i.e. the summed areas of the Gaussian curves representing the broad band between $3100 \mathrm{~cm}^{-1}$ and $3500 \mathrm{~cm}^{-1}$ ). The progression of $\varphi$ with time at fixed radial positions is shown in Fig. 5a. $\varphi_{0}$ is here set to 1 (the fractional O-D concentration maintained at the edge of the disk) and $\varphi_{1}$ is here set to 0 (the O-D concentration everywhere except the edge at $t=0$ ).

To determine $D_{\text {water }}$ at a given RH, a surface fit of Eq. (2) with the diffusion coefficient as the sole variable parameter is performed to the measured values of $\varphi(r t)$, again using the Levenberg-Marquardt technique. Figure $5 b$ shows an example of this surface fit to a set of data, where each measured data point is connected to the fitted surface by a black line for comparison. Due to the finite size of the laser spot (estimated by the manufacturers as $1.3 \mu \mathrm{m}$ ), measured values of 

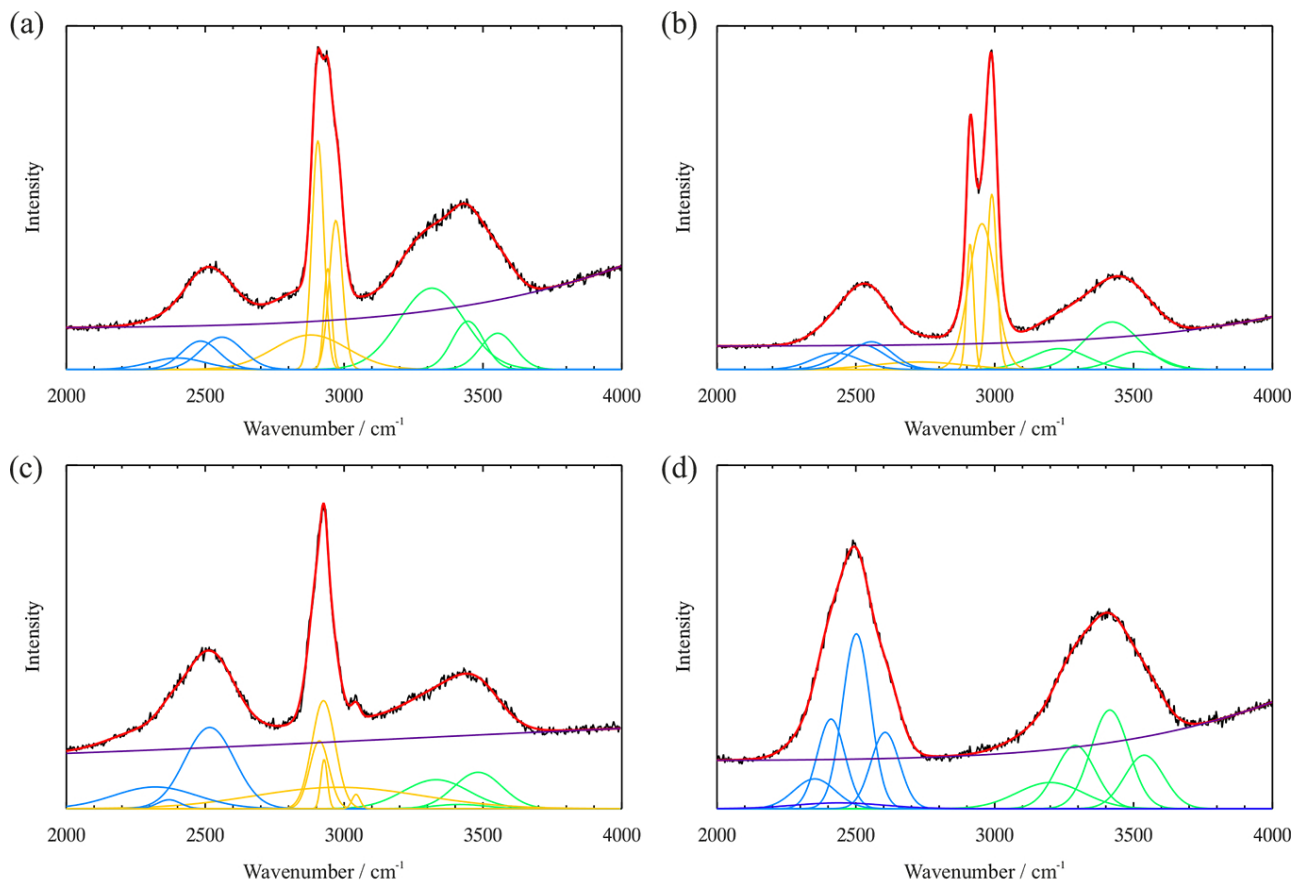

Fig. 4. Example fits to the Raman spectra of (a) sucrose, (b) levoglucosan, (c) $\mathrm{MgSO}_{4}$ and (d) raffinose/M5AS. Raw data is shown in black, green peaks are fitted to the O-H (and $\mathrm{NH}_{4}^{+}$in raffinose/M5AS) stretch, blue peaks are fitted to the O-D (and ND $\mathrm{N}_{4}^{+}$in raffinose/M5AS) stretch, orange peaks are fitted to the $\mathrm{C}-\mathrm{H}$ stretch, and the background fit is shown in purple. The sum of all fitted peaks is shown in red. Green and blue peaks were allowed to vary as H/D exchange took place; orange peaks were more tightly constrained.

$\varphi$ are least reliable where the radial concentration gradient is changing rapidly.

It is evident from the complete disappearance of the $\mathrm{O}-\mathrm{H}$ stretch band in Fig. 3 that H/D exchange occurs not only in the water molecules of the sample, but also in the hydroxyl groups of the organics. A large difference between the rates of these two exchanges would complicate the determination of the diffusion coefficient. However, at $90 \%$ RH, complete $\mathrm{H} / \mathrm{D}$ exchange at the centre of a disk was observed on the timescale of minutes. Given that measurements at RHs lower than $\sim 70 \%$ took significantly longer than this, and that the calculated diffusion coefficients were several orders of magnitude lower, we conclude that the limiting step here is diffusion, not H/D exchange rate. We note, however, that for measurements between 70 and $90 \% \mathrm{RH}$ the procedure may introduce some uncertainty. The determined diffusion coefficient may thus be slightly lower than the true value.

\section{Results and discussion}

The determined diffusion coefficients of $\mathrm{D}_{2} \mathrm{O}$ in sucrose, levoglucosan, magnesium sulfate and raffinose/M5AS as a function of water activity, at $23.5^{\circ} \mathrm{C}$, are shown in Fig. 6. The upper error bars shown for $D_{\text {water }}$ represent the value of $D_{\text {water }}$ calculated using the highest value measured for the upper limit on the disk's radius (usually that calculated from the
Table 1. Fit parameters $a$ to $d$ used in Eq. (4) for $D_{\text {water }}\left(\mathrm{a}_{\mathrm{w}}\right)$.

\begin{tabular}{lllll}
\hline & $\mathrm{a}$ & $\mathrm{b}$ & $\mathrm{c}$ & $\mathrm{d}$ \\
\hline Sucrose & -20.89 & 25.92 & -26.97 & 13.25 \\
Levoglucosan & -18.41 & 31.10 & -44.43 & 23.12 \\
Raffinose/M5AS & -17.21 & 24.00 & -32.50 & 17.02 \\
\hline
\end{tabular}

three edge measurements before exposure to $\mathrm{D}_{2} \mathrm{O}$ vapour), with a time delay of $95 \mathrm{~s}$, and include the random error in the surface fit due to errors in $\varphi$. The lower error bars shown for $D_{\text {water }}$ represent the value of $D_{\text {water }}$ calculated using the lowest value measured for lower limit on the disk's radius (usually that calculated from the three edge measurements after exposure to $\mathrm{D}_{2} \mathrm{O}$ vapour), with a time delay of $10 \mathrm{~s}$, and also include the random error in the surface fit due to errors in $\varphi$. Lines are fitted to the data as follows:

$\log _{10} D_{\mathrm{water}}=a+b a_{w}+c a_{\mathrm{w}}^{2}+d a_{\mathrm{w}}^{3}$

where $a, b, c$ and $d$ are empirically fitted parameters detailed in Table 1. The fits for all substances converge to the diffusion coefficient for water in water at a water activity of 1.0 (Holz et al., 2000).

The diffusion of $\mathrm{D}_{2} \mathrm{O}$ is expected to be slightly slower than that of $\mathrm{H}_{2} \mathrm{O}$. As a guide, the ratio of the self-diffusion coefficients of $\mathrm{H}_{2} \mathrm{O}$ and $\mathrm{D}_{2} \mathrm{O}$ have been found to lie in the range 
(a)

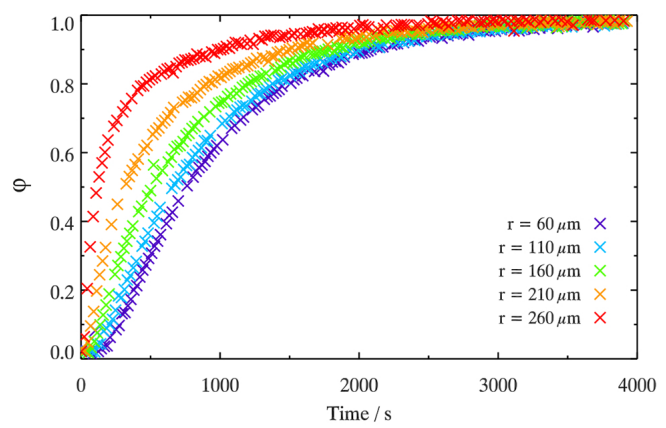

(b)

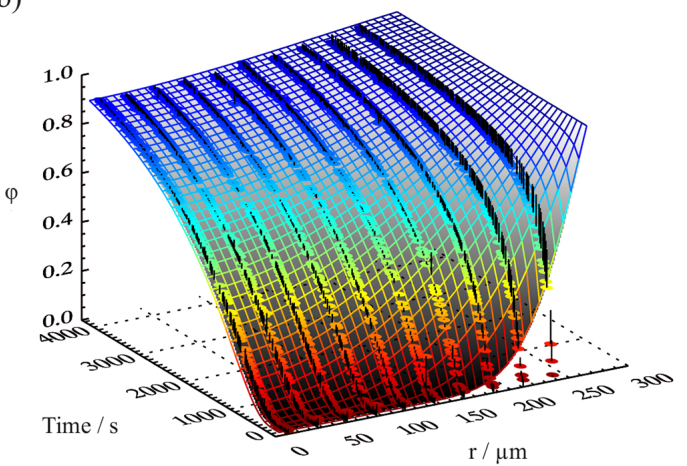

(c)

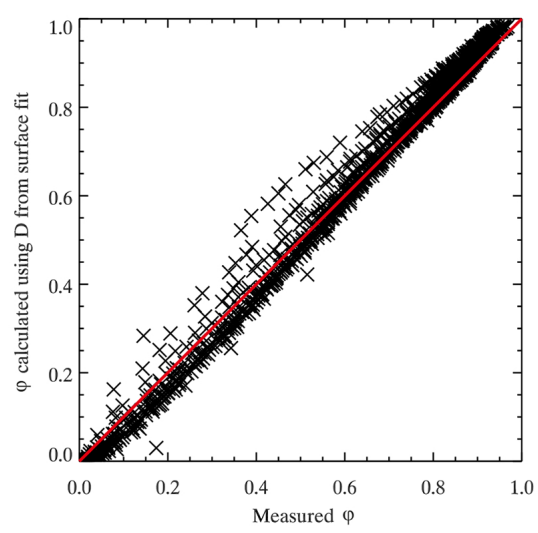

Fig. 5. (a) Plot of fractional concentration of O-D bonds, $\varphi$, as a function of time after switch from $\mathrm{H}_{2} \mathrm{O}$ to $\mathrm{D}_{2} \mathrm{O}$ vapour in a $278 \mu \mathrm{m}$ (radius) levoglucosan disk at $60 \% \mathrm{RH}$. Colours indicate radial distance (where $r=0 \mu \mathrm{m}$ is the centre of the disk): red data points are near the edge, blue are near the centre. This was a one-off experiment in which data was repeatedly collected at five specific radial positions, for the purpose of visualising how concentration changed at a fixed location over time. (b) Plot of the fractional concentration of O-D bonds, $\varphi$, as a function of radial distance and time after switch from $\mathrm{H}_{2} \mathrm{O}$ to $\mathrm{D}_{2} \mathrm{O}$ vapour in the levoglucosan disk at $50 \%$ $\mathrm{RH}$. The grid shows the surface fit to the data, the collected data points are joined to the grid by black lines. The colour corresponds to the value of $\varphi$. (c) A one-to-one plot showing the measured $\varphi$ vs. $\varphi$ according to the fit, also for levoglucosan at $50 \% \mathrm{RH}$.

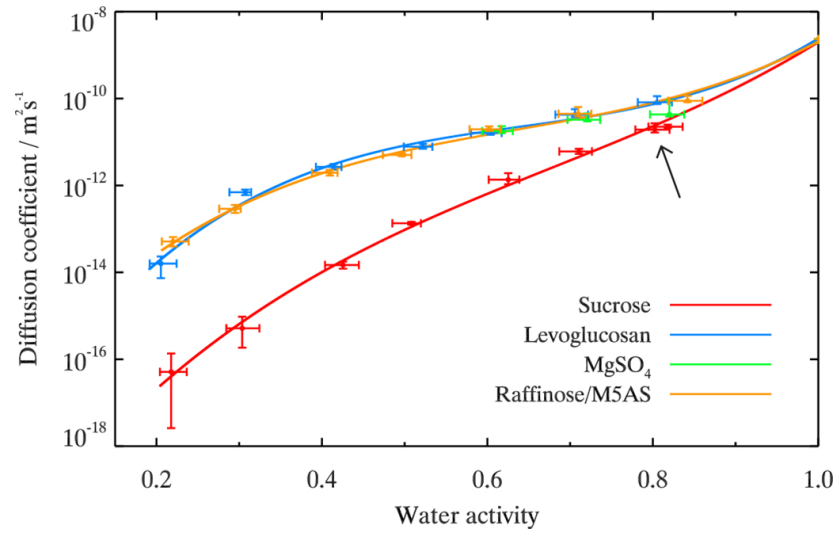

Fig. 6. Measured water diffusion coefficients of sucrose, levoglucosan, magnesium sulfate and raffinose/M5AS. Lines are fitted to the data with an empirical polynomial fit (Eq. 4). The arrow indicates a measurement performed on a sucrose disk which had previously been held at $50^{\circ} \mathrm{C}$ for a week. We infer from the fact that this data point agrees well with its neighbour that equilibrating the samples at high temperatures does not alter their diffusion properties.

1.10 to 1.25 (Mills, 1973; Svishchev and Kusalik, 1994; Liu and Macedo, 1995). However, given that the measured values cover 6 orders of magnitude, the diffusion coefficient of $\mathrm{D}_{2} \mathrm{O}$ can be taken as a good approximation for that of $\mathrm{H}_{2} \mathrm{O}$.

\subsection{Sucrose - comparison with literature data}

The diffusion coefficients of water in aqueous sucrose solutions are compared to literature data in Fig. 7 and are in good agreement for water activities between 0.5 and 0.7. Below a water activity of 0.5 , where the He et al. (2006) and Zobrist et al. (2011) parameterisations deviate from each other, the fit to our data lies between the available literature values, but seems to follow the trend of the free-volume model (He et al., 2006). This is consistent with the observation by Tong et al. (2011) that the diffusion coefficient reported by Zobrist et al. (2011) for a $95 \%$ sucrose solution (a water activity of 0.28 ) is too large to explain their observed droplet size changes.

The slight deviations from literature values at high water activities may be due to a number of factors. When diffusion is fast, the radial progression of the concentration gradient may be limited by something other than water diffusion, possibly the slower H/D exchange in hydroxyl groups (as discussed in Sect. 2.4). The fractional concentration of $\mathrm{O}-\mathrm{D}$ bonds (relative to the total O-D plus O-H bonds) in the gas phase at the edge of the disk cannot instantaneously become 1 when the switch is made from $\mathrm{H}_{2} \mathrm{O}$ to $\mathrm{D}_{2} \mathrm{O}$. There will be an unavoidable period of time in which a mixture of $\mathrm{H}_{2} \mathrm{O}$ and $\mathrm{D}_{2} \mathrm{O}$ vapours is present; the nearer the duration of this switchover is to the timescale of the measurement, the more likely it is to lead to errors. 


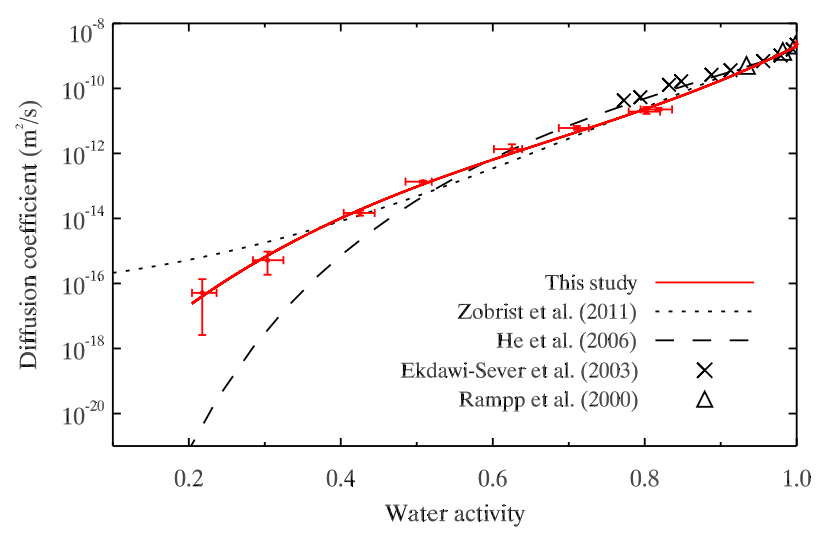

Fig. 7. Measured diffusion coefficients of water in aqueous sucrose solutions, with comparison to the parameterisations for sucrose solutions given in Zobrist et al. (2011) and He et al. (2006), and the NMR measurements of Ekdawi-Sever et al. (2003) and Rampp et al. (2000).

\subsection{Timescales for water diffusion}

The characteristic half-time for diffusion into a spherical particle of radius $r$ at constant water activity is given by Seinfeld and Pandis (2006):

$\tau_{1 / 2}=\frac{r^{2}}{\pi^{2} D \cdot \ln (2)}$.

Note that this is the diffusion timescale for water diffusing into a droplet at constant water activity and therefore $D$ does not change. It may be of interest to know the timescales over which a droplet would respond to changes in RH under certain atmospheric circumstances. This is not a simple calculation due to the plasticising effect of water in these aqueous solutions - the diffusion coefficient is a function of concentration and would vary radially as a droplet increased or decreased in size. In order to model the response of a droplet to a change in humidity a model of the time response of a droplet undergoing water uptake and loss would be required. This is the subject of ongoing work and beyond the scope of this paper. In this study, we use $\tau_{1 / 2}$ to give basic information about the rate at which water molecules diffuse within a droplet at a given relative humidity.

Figure 8a shows these timescales for water diffusing into sucrose, levoglucosan and raffinose/M5AS aqueous spherical droplets of radii between $100 \mathrm{~nm}$ and $1 \mathrm{~mm}$ at $20 \%$ RH. For levoglucosan and raffinose/M5AS, water diffusion timescales are faster than $1 \mathrm{~s}$ in particles smaller than $250 \mathrm{~nm}$ in radius at room temperature. For sucrose these timescales are on the order of minutes to hours. Under these conditions the calorimetry data presented by Zobrist et al. (2008) suggest that aqueous sucrose exists in a glassy state. As Zobrist et al. (2011) point out, even though particles may exist in what is by definition a glassy state, water diffusion is not necessarily arrested. Nevertheless, the kinetic limitation could be important for growth measurements in aerosol instruments which operate on short timescales, such as the HTDMA (Hersey et al., 2013). In addition, diffusion coefficients decrease with temperature and thus under common atmospheric conditions these timescales are expected to be far greater.

Water diffusion coefficients measured in this study have been used to calculate water diffusion timescales as a function of RH in a droplet of $100 \mathrm{~nm}$ radius, according to Eq. (5); these are plotted as red dots in Fig. 8b. These timescales have also been calculated using the water diffusion coefficients given in Zobrist et al. (2011) for comparison. To illustrate the magnitude of error that would be encountered when estimating these water diffusion timescales from a viscosity measurement, the Stokes-Einstein relation was used with the viscosity measurements of Power et al. (2013) to estimate $D$ in Eq. (5). The resulting timescales are shown as black crosses. There is a discrepancy of more than 5 orders of magnitude between the two data sets at $\sim 30 \% \mathrm{RH}$ and $\sim 2$ orders at $62 \%$ RH. Again, this demonstrates the importance of quantifying diffusion in atmospheric aerosol.

\subsection{Levoglucosan - relationship to bounce factor data}

Diffusion coefficients of water in levoglucosan were found to be significantly higher than those in sucrose for the same RH and correspond to diffusion in a high-viscosity liquid. This is consistent with the glass transition curve given by Lienhard et al. (2012) which shows that the glass transition temperatures of aqueous levoglucosan solutions of water activities above 0.2 are below $236 \mathrm{~K}$.

Saukko et al. (2012) determined the bounced fraction of aqueous levoglucosan aerosol by impacting the aerosol onto a substrate and counting the number of particles which rebounded - a high bounce fraction is considered to indicate high viscosity, whilst a low bounce fraction implies low viscosity. As noted by Saukko et al. (2012), high-viscosity liquids and semi-solids have similar bounce behaviour to glasses and crystalline solids: bounce fractions of around 0.8 were measured for both high-viscosity liquid levoglucosan and crystalline ammonium sulfate. Figure 9 shows diffusion half-lives of $100 \mathrm{~nm}$ radius levoglucosan droplets as a function of water activity, as calculated using Eq. (5), compared with bounce fraction data. Even at low RH, this characteristic timescale for diffusion in levoglucosan is less than $0.1 \mathrm{~s}$. Zobrist et al. (2011) measured water diffusion coefficients in glassy particles (which would presumably have similarly high bounce fractions to low RH levoglucosan) as low as $10^{-24} \mathrm{~m}^{2} \mathrm{~s}^{-1}$, which, according to Eq. (5), would have diffusion half-lives of over 100 years. Thus, these results reiterate what is already accepted about the bounce technique: although bounce fraction measurements are useful in determining particle phase in the relevant size range, they alone cannot yet distinguish between particles in which diffusion 
(a)

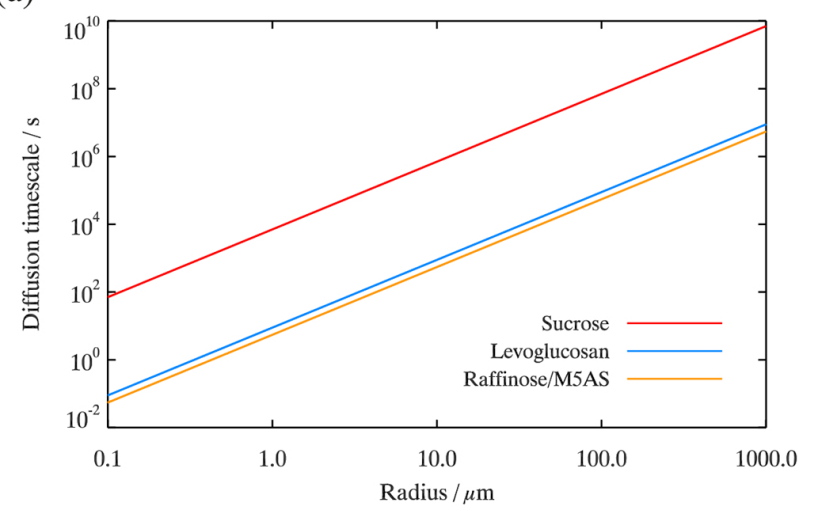

(b)

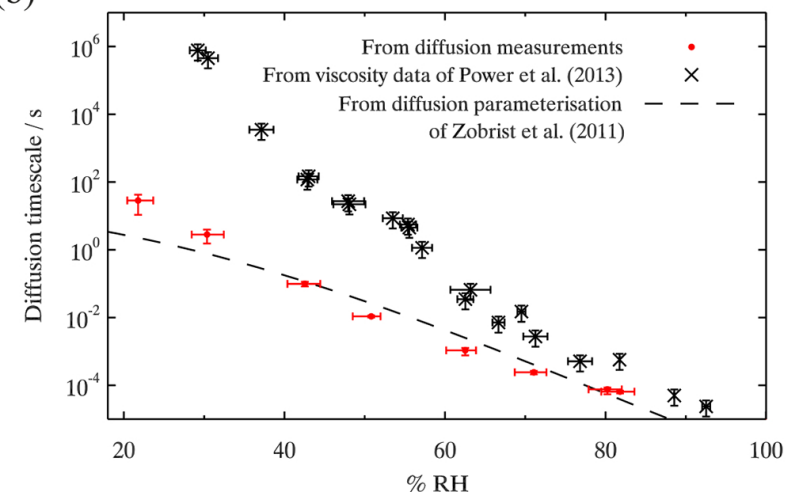

Fig. 8. (a) Water diffusion timescales as a function of radius for spherical droplets at $20 \% \mathrm{RH}$, calculated according to Eq. (5). Sucrose is shown in red, levoglucosan in blue and raffinose/M5AS in orange. (b) Water diffusion timescales (Eq. 5) as a function of relative humidity for $100 \mathrm{~nm}$ particles. Red dots show timescales calculated using water diffusion coefficients measured in this study, the dashed black line shows these timescales using the water diffusion coefficient parameterisation given in Zobrist et al. (2011). Black crosses are calculated using the Stokes-Einstein relation with viscosity data from Power et al. (2013) (error bars correspond to a water molecular diameter uncertainty of $0.2 \pm 0.1 \mathrm{~nm}$ ).

of a small molecule such as water occurs on timescales of milliseconds and those in which it takes years (Saukko et al., 2012). This underlines the importance of quantitative diffusion measurements for the understanding of high-viscosity atmospheric aerosol.

\section{4 $\mathrm{MgSO}_{4}$ gel formation}

Figure 10 shows the diffusion surface fits for magnesium sulfate between 82 and $51 \% \mathrm{RH}$. There is a distinct shift from Fickian diffusion between 62 (Fig. 10c) and $51 \%$ RH (Fig. 10d), where it is no longer possible to find a fit to the data using Eq. (2). There is also a corresponding structural change in the sample. At $62 \%$ and higher $\mathrm{RH}$, the sample appeared homogeneous when inspected with an optical microscope, whereas at $51 \% \mathrm{RH}$ there was some structure within the disk (Fig. 11a). This structure had a strong effect

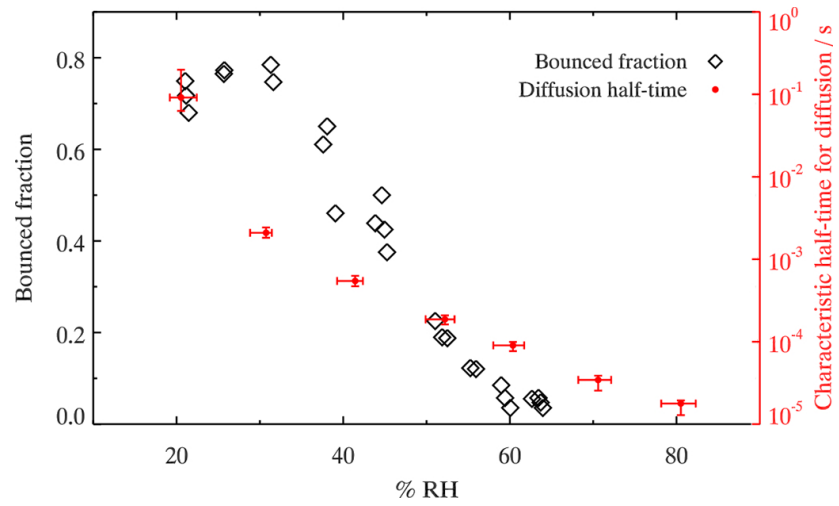

Fig. 9. Characteristic timescales for diffusion of $\mathrm{D}_{2} \mathrm{O}$ in $100 \mathrm{~nm}$ aqueous levoglucosan aerosol particles (red dots), compared with bounce fraction data from Saukko et al. (2012) (black diamonds).

on $\mathrm{D}_{2} \mathrm{O}$ diffusion. Figure $11 \mathrm{~b}$ shows a map of $\varphi$ for the area highlighted in Fig. 11a after 1 day's exposure to $\mathrm{D}_{2} \mathrm{O}$ vapour. Within the approximately triangular structure $\mathrm{D}_{2} \mathrm{O}$ replaced the $\mathrm{H}_{2} \mathrm{O}$, whereas very little or no exchange occurred in the other regions.

Magnesium sulfate is known to form a gel due to the formation of a complex ion-induced network; this network structure has been shown to inhibit water mass transfer within the gel (Chan et al., 1998; Zhang and Chan, 2000). The transition to a gel has been variously reported to occur between 55 and 30\% RH (Wang et al., 2005; Zhao et al., 2006; Li et al., 2011; Davies et al., 2012), in agreement with our findings. The marked change in the water diffusion process at the gel transition is completely different to the gradual decrease in the diffusion coefficient seen in the aqueous organic liquids. For this reason, it is important to note the clear distinction between semi-solids such as gels or rubbers and highly viscous liquids.

\section{Summary}

The existence of aerosol as highly viscous liquids and amorphous glassy solids may have a profound effect on their interactions with water vapour and other chemical species in the atmosphere. It is therefore important to quantify diffusion in ultra-viscous and amorphous solid states. In this paper we describe a new experimental system for quantifying the diffusion coefficient of water molecules in aqueous solutions, with diffusion coefficients measured between $10^{-16}$ and $10^{-10} \mathrm{~m}^{2} \mathrm{~s}^{-1}$. This range corresponds to solutions from the glassy to liquid states. We show that this methodology, which makes use of $\mathrm{D}_{2} \mathrm{O}$ as an isotopic tracer, produces water diffusion coefficients for sucrose solutions in good agreement with those in the literature. New data for water diffusion coefficients in aqueous solutions of $\mathrm{MgSO}_{4}$, levoglucosan and a mixture of raffinose, carboxylic acids and ammonium sulfate are also presented for the first time. 

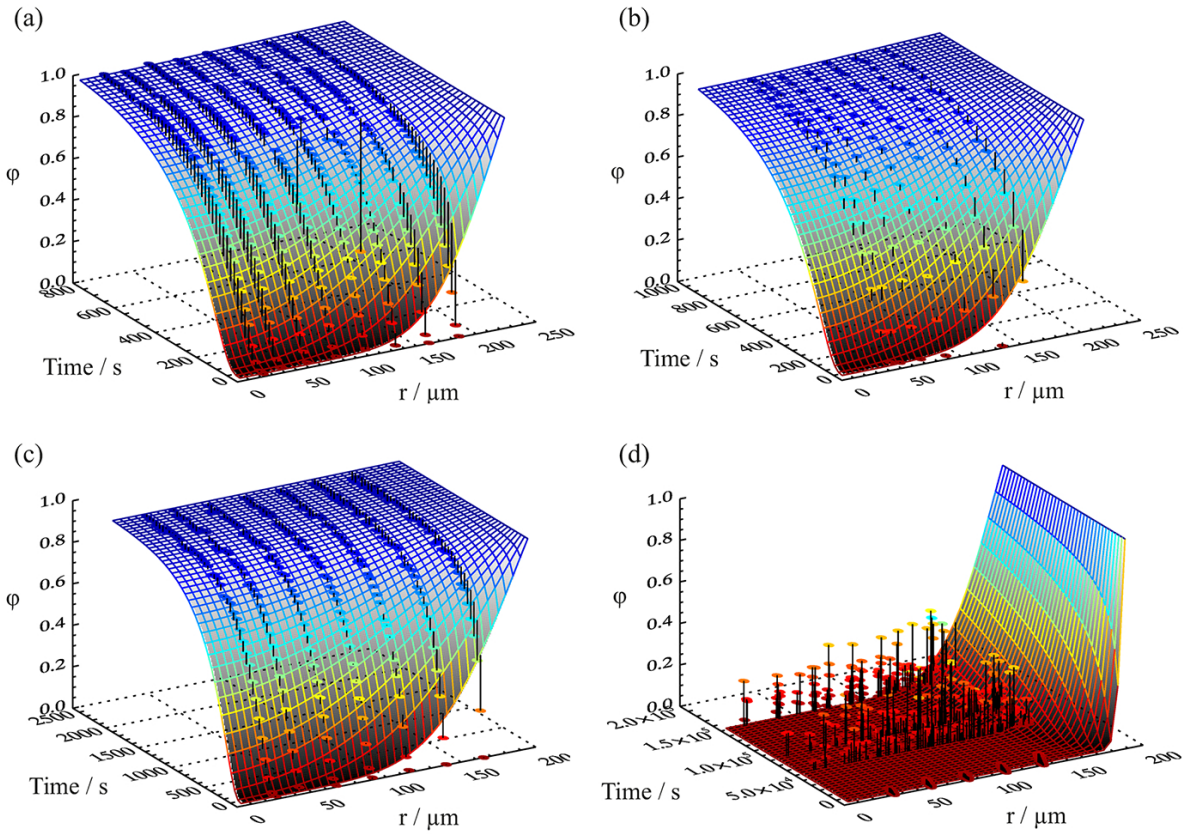

Fig. 10. Surface fits to $\varphi$ as a function of radial position and time, using Eq. (2), at an RH of (a) $82 \pm 2 \%$, (b) $72 \pm 2 \%$, (c) $62 \pm 2 \%$ and (d) $51 \pm 2 \%$ for magnesium sulfate. The quality of the fit is poor at $51 \% \mathrm{RH}$, which reflects the lack of homogeneity in the sample.

(b)

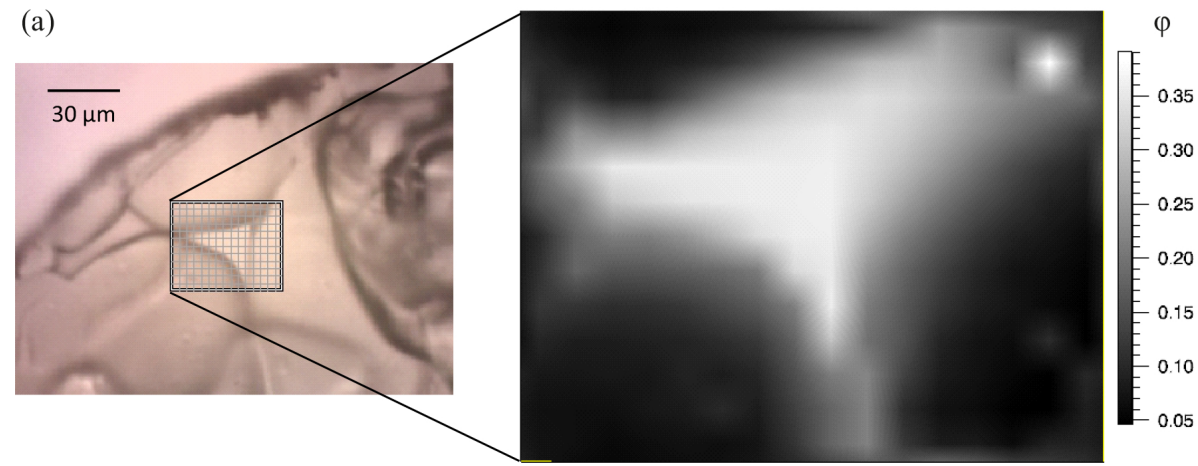

Fig. 11. (a) Visible inhomogeneities in the magnesium sulfate disk at $51 \% \mathrm{RH}$. This disk was exposed to $\mathrm{D}_{2} \mathrm{O}$ vapour for one day before a Raman map was acquired across the grid shown. (b) Fractional concentration of O-D bonds after one day. It appears that $\mathrm{D}_{2} \mathrm{O}$ diffused faster into the central triangular shape than the surrounding regions.

Using these measured water diffusion coefficients we predict diffusion timescales for aerosol-sized particles $(\sim 100 \mathrm{~nm})$ at room temperature under constant $\mathrm{RH}$ conditions, and show that just below the glass transition it takes minutes before equilibrium with water vapour is achieved. This is a vastly shorter timescale than one would expect based on the Stokes-Einstein equation, which has been used to relate diffusion to viscosity in the past. Our results reinforce previous studies showing that the Stokes-Einstein relationship is inappropriate in the regime of the glass transition (Champion et al., 1997; Rampp et al., 2000; Power et al., 2013). Even though the diffusion timescale is much shorter than predicted by the Stokes-Einstein equation, it is still long in comparison to the timescale needed when using thermodenuders and HTDMAs (seconds). Hence, some caution must be applied to the interpretation of results from measurements. In addition, we show for levoglucosan that a high bounce fraction does not necessarily mean long water diffusion timescales.

It is important to note that we have only measured diffusion coefficients for water, whereas diffusion of other gaseous species (e.g. $\mathrm{NO}_{2}, \mathrm{SO}_{2}, \mathrm{H}_{2} \mathrm{O}_{2}$ and $\mathrm{O}_{3}$ ) into aerosol is important for chemistry, and diffusion of organic molecules is important for aerosol growth and evaporation. It is unclear how well (or poorly) the Stokes-Einstein equation predicts diffusion of these other atmospherically important 
species and dedicated diffusion measurements are therefore highly desirable.

Acknowledgements. We thank T. Windross for constructing the $\mathrm{RH}$ and temperature controlled chamber. Financial support for this work was provided by the European Research Council (FP7, 240449 ICE) and the Natural Environment Research Council (NE/K004417/1, NE/I020059/1, NE/I013466/1).

Edited by: D. Topping

\section{References}

Abramson, E., Imre, D., Beranek, J., Wilson, J., and Zelenyuk, A.: Experimental determination of chemical diffusion within secondary organic aerosol particles, Phys. Chem. Chem. Phys., 15, 2983-2991, doi:10.1039/c2cp44013j, 2013.

Ahlqvist, M. U. A. and Taylor, L. S.: Water diffusion in hydrated crystalline and amorphous sugars monitored using $\mathrm{h} / \mathrm{d}$ exchange, J. Pharm. Sci., 91, 690-698, doi:10.1002/jps.10068, 2002.

Atkinson, J. D., Murray, B. J., Woodhouse, M. T., Whale, T. F., Baustian, K. J., Carslaw, K. S., Dobbie, S., O'Sullivan, D., and Malkin, T. L.: The importance of feldspar for ice nucleation by mineral dust in mixed-phase clouds, Nature, 498, 355-358, doi:10.1038/nature12278, 2013.

Bahreini, R., Keywood, M. D., Ng, N. L., Varutbangkul, V., Gao, S., Flagan, R. C., Seinfeld, J. H., Worsnop, D. R., and Jimenez, J. L.: Measurements of secondary organic aerosol from oxidation of cycloalkenes, terpenes, and m-xylene using an aerodyne aerosol mass spectrometer, Environ. Sci. Technol., 39, 56745688, doi:10.1021/es048061a, 2005.

Bartell, L. S. and Roskos, R. R.: Isotope effects on molar volume and surface tension - simple theoretical model and experimental data for hydrocarbons, J. Chem. Phys., 44, 457-463, doi:10.1063/1.1726709, 1966.

Baustian, K. J., Wise, M. E., Jensen, E. J., Schill, G. P., Freedman, M. A., and Tolbert, M. A.: State transformations and ice nucleation in amorphous (semi-)solid organic aerosol, Atmos. Chem. Phys., 13, 5615-5628, doi:10.5194/acp-13-5615-2013, 2013.

Bodsworth, A., Zobrist, B., and Bertram, A. K.: Inhibition of efflorescence in mixed organic-inorganic particles at temperatures less than $250 \mathrm{k}$, Phys. Chem. Chem. Phys., 12, 12259-12266, doi:10.1039/c0cp00572j, 2010.

Bones, D. L., Reid, J. P., Lienhard, D. M., and Krieger, U. K.: Comparing the mechanism of water condensation and evaporation in glassy aerosol, P. Natl. Acad. Sci. USA, 109, 11613-11618, doi:10.1073/pnas.1200691109, 2012.

Bowman, F.: Introduction to bessel functions, Dover Publications, New York, 1958.

Broadley, S. L., Murray, B. J., Herbert, R. J., Atkinson, J. D., Dobbie, S., Malkin, T. L., Condliffe, E., and Neve, L.: Immersion mode heterogeneous ice nucleation by an illite rich powder representative of atmospheric mineral dust, Atmos. Chem. Phys., 12, 287-307, doi:10.5194/acp-12-287-2012, 2012.

Cappa, C. D. and Wilson, K. R.: Evolution of organic aerosol mass spectra upon heating: implications for OA phase and partitioning behavior, Atmos. Chem. Phys., 11, 1895-1911, doi:10.5194/acp11-1895-2011, 2011.
Champion, D., Hervet, H., Blond, G., Le Meste, M., and Simatos, D.: Translational diffusion in sucrose solutions in the vicinity of their glass transition temperature, J. Phys. Chem. B, 101, 1067410679, doi:10.1021/jp971899i, 1997.

Chan, C. K., Flagan, R. C., and Seinfeld, J. H.: In situ study of single aqueous droplet solidification of ceramic precursors used for spray pyrolysis, J. Am. Ceram. Soc., 81, 646-648, doi:10.1111/j.1151-2916.1998.tb02384.x, 1998.

Davies, J. F., Haddrell, A. E., Miles, R. E. H., Bull, C. R., and Reid, J. P.: Bulk, surface, and gas-phase limited water transport in aerosol, J. Phys. Chem. A, 116, 10987-10998, doi:10.1021/jp3086667, 2012.

Debenedetti, P. G. and Stillinger, F. H.: Supercooled liquids and the glass transition, Nature, 410, 259-267, doi:10.1038/35065704, 2001.

Decesari, S., Fuzzi, S., Facchini, M. C., Mircea, M., Emblico, L., Cavalli, F., Maenhaut, W., Chi, X., Schkolnik, G., Falkovich, A., Rudich, Y., Claeys, M., Pashynska, V., Vas, G., Kourtchev, I., Vermeylen, R., Hoffer, A., Andreae, M. O., Tagliavini, E., Moretti, F., and Artaxo, P.: Characterization of the organic composition of aerosols from Rondônia, Brazil, during the LBASMOCC 2002 experiment and its representation through model compounds, Atmos. Chem. Phys., 6, 375-402, doi:10.5194/acp6-375-2006, 2006.

Ekdawi-Sever, N., de Pablo, J. J., Feick, E., and von Meerwall, E.: Diffusion of sucrose and $\alpha, \alpha$-trehalose in aqueous solutions, J. Phys. Chem. A, 107, 936-943, doi:10.1021/jp020187b, 2003.

Ha, Z. and Chan, C. K.: The water activities of $\operatorname{mgcl} 2, \operatorname{mg}($ no3)2, mgso4, and their mixtures, Aerosol Sci. Tech., 31, 154-169, doi:10.1080/027868299304219, 1999.

He, X., Fowler, A., and Toner, M.: Water activity and mobility in solutions of glycerol and small molecular weight sugars: Implication for cryo- and lyopreservation, J. Appl. Phys., 100, 074702074711, 2006.

Hersey, S. P., Craven, J. S., Metcalf, A. R., Lin, J., Lathem, T., Suski, K. J., Cahill, J. F., Duong, H. T., Sorooshian, A., Jonsson, H. H., Shiraiwa, M., Zuend, A., Nenes, A., Prather, K. A., Flagan, R. C., and Seinfeld, J. H.: Composition and hygroscopicity of the los angeles aerosol: Calnex, J. Geophys. Res.-Atmos., 118, 3016-3036, doi:10.1002/jgrd.50307, 2013.

Holz, M., Heil, S. R., and Sacco, A.: Temperature-dependent selfdiffusion coefficients of water and six selected molecular liquids for calibration in accurate $1 \mathrm{~h}$ nmr pfg measurements, Phys. Chem. Chem. Phys., 2, 4740-4742, doi:10.1039/b005319h, 2000.

Knopf, D. A., Anthony, L. M., and Bertram, A. K.: Reactive uptake of 03 by multicomponent and multiphase mixtures containing oleic acid, J. Phys. Chem. A, 109, 5579-5589, doi:10.1021/jp0512513, 2005.

Kohen, A. and Limbach, H. H.: Isotope effects in chemistry and biology, Taylor \& Francis, Boca Raton, FL, 2010.

Koop, T., Bookhold, J., Shiraiwa, M., and Pöschl, U.: Glass transition and phase state of organic compounds: Dependency on molecular properties and implications for secondary organic aerosols in the atmosphere, Phys. Chem. Chem. Phys., 13, 19238-19255, doi:10.1039/c1cp22617g, 2011.

Kuwata, M. and Martin, S. T.: Phase of atmospheric secondary organic material affects its reactivity, P. Natl. Acad. Sci. USA, 109, 17354-17359, doi:10.1073/pnas.1209071109, 2012. 
Li, K.-K., Wang, F., Zeng, G., Reid, J. P., and Zhang, Y.-H.: Probing the time scale for bulk equilibration and mass transport of water in amorphous inorganic aerosol, J. Phys. Chem. B, 115, 1439714403, doi:10.1021/jp209379f, 2011.

Lienhard, D. M., Bones, D. L., Zuend, A., Krieger, U. K., Reid, J. P., and Peter, T.: Measurements of thermodynamic and optical properties of selected aqueous organic and organic-inorganic mixtures of atmospheric relevance, J. Phys. Chem. A, 116, 99549968, doi:10.1021/jp3055872, 2012.

Liu, C., Shi, S., Weschler, C., Zhao, B., and Zhang, Y.: Analysis of the dynamic interaction between svocs and airborne particles, Aerosol Sci. Tech., 47, 125-136, doi:10.1080/02786826.2012.730163, 2012.

Liu, H. and Macedo, E. A.: Accurate correlations for the selfdiffusion coefficients of $\mathrm{CO}_{2}, \mathrm{CH}_{4}, \mathrm{C}_{2} \mathrm{H}_{4}, \mathrm{H}_{2} \mathrm{O}$, and $\mathrm{D}_{2} \mathrm{O}$ over wide ranges of temperature and pressure, J. Supercrit. Fluid, 8, 310-317, doi:10.1016/0896-8446(95)90006-3, 1995.

Markwardt, C. B.: Non-linear least squares fitting in idl with mpfit, in: ASP Conference Series, Astronomical Data Analysis Software and Systems XVIII, Quebec, Canada, 2008, 251-254, 2008.

Matsunaga, N. and Nagashima, A.: Saturation vapor pressure and critical constants of $\mathrm{H}_{2} \mathrm{O}, \mathrm{D}_{2} \mathrm{O}, \mathrm{T}_{2} \mathrm{O}$, and their isotopic mixtures, Int. J. Thermophys., 8, 681-694, doi:10.1007/bf00500788, 1987.

Mikhailov, E., Vlasenko, S., Martin, S. T., Koop, T., and Pöschl, U.: Amorphous and crystalline aerosol particles interacting with water vapor: conceptual framework and experimental evidence for restructuring, phase transitions and kinetic limitations, Atmos. Chem. Phys., 9, 9491-9522, doi:10.5194/acp-9-9491-2009, 2009.

Mills, R.: Self-diffusion in normal and heavy water in the range 145.Deg, J. Phys. Chem., 77, 685-688, doi:10.1021/j100624a025, 1973.

Murray, B. J.: Inhibition of ice crystallisation in highly viscous aqueous organic acid droplets, Atmos. Chem. Phys., 8, 54235433, doi:10.5194/acp-8-5423-2008, 2008.

Murray, B. J. and Bertram, A. K.: Inhibition of solute crystallisation in aqueous $\mathrm{H}^{+}-\mathrm{NH} 4+-\mathrm{SO} 42-\mathrm{H}_{2} \mathrm{O}$ droplets, Phys. Chem. Chem. Phys., 10, 3287-3301, doi:10.1039/B802216j, 2008.

Murray, B. J., Broadley, S. L., Wilson, T. W., Bull, S. J., Wills, R. H., Christenson, H. K., and Murray, E. J.: Kinetics of the homogeneous freezing of water, Phys. Chem. Chem. Phys., 12, 1038010387, doi:10.1039/c003297b, 2010a.

Murray, B. J., Wilson, T. W., Dobbie, S., Cui, Z. Q., Al-Jumur, S. M. R. K., Mohler, O., Schnaiter, M., Wagner, R., Benz, S., Niemand, M., Saathoff, H., Ebert, V., Wagner, S., and Karcher, B.: Heterogeneous nucleation of ice particles on glassy aerosols under cirrus conditions, Nat. Geosci., 3, 233-237, doi:10.1038/Ngeo817, 2010 b.

Murray, B. J., Broadley, S. L., Wilson, T. W., Atkinson, J. D., and Wills, R. H.: Heterogeneous freezing of water droplets containing kaolinite particles, Atmos. Chem. Phys., 11, 4191-4207, doi:10.5194/acp-11-4191-2011, 2011.

Murray, B. J., Haddrell, A. E., Peppe, S., Davies, J. F., Reid, J. P., O’Sullivan, D., Price, H. C., Kumar, R., Saunders, R. W., Plane, J. M. C., Umo, N. S., and Wilson, T. W.: Glass formation and unusual hygroscopic growth of iodic acid solution droplets with relevance for iodine mediated particle formation in the marine boundary layer, Atmos. Chem. Phys., 12, 8575-8587, doi:10.5194/acp-12-8575-2012, 2012.
Parker, R. and Ring, S. G.: Diffusion in maltose-water mixtures at temperatures close to the glass transition, Carbohyd. Res., 273, 147-155, doi:10.1016/0008-6215(95)00120-i, 1995.

Parsons, M. T., Knopf, D. A., and Bertram, A. K.: Deliquescence and crystallization of ammonium sulfate particles internally mixed with water-soluble organic compounds, J. Phys. Chem. A, 108, 11600-11608, doi:10.1021/jp0462862, 2004.

Perraud, V., Bruns, E. A., Ezell, M. J., Johnson, S. N., Yu, Y., Alexander, M. L., Zelenyuk, A., Imre, D., Chang, W. L., Dabdub, D., Pankow, J. F., and Finlayson-Pitts, B. J.: Nonequilibrium atmospheric secondary organic aerosol formation and growth, P. Natl. Acad. Sci. USA, 109, 2836-2841, doi:10.1073/pnas.1119909109, 2012.

Pfrang, C., Shiraiwa, M., and Pöschl, U.: Chemical ageing and transformation of diffusivity in semi-solid multi-component organic aerosol particles, Atmos. Chem. Phys., 11, 7343-7354, doi:10.5194/acp-11-7343-2011, 2011.

Pöschl, U.: Atmospheric aerosols: Composition, transformation, climate and health effects, Angew. Chem. Int. Edit., 44, 7520 7540, doi:10.1002/anie.200501122, 2005.

Power, R. M., Simpson, S. H., Reid, J. P., and Hudson, A. J.: The transition from liquid to solid-like behaviour in ultrahigh viscosity aerosol particles, Chem. Sci., 4, 2597-2604, doi:10.1039/c3sc50682g, 2013.

Prenni, A. J., DeMott, P. J., Kreidenweis, S. M., Sherman, D. E., Russell, L. M., and Ming, Y.: The effects of low molecular weight dicarboxylic acids on cloud formation, J. Phys. Chem. A, 105, 11240-11248, doi:10.1021/jp012427d, 2001.

Rampp, M., Buttersack, C., and Lüdemann, H.-D.: C,t-dependence of the viscosity and the self-diffusion coefficients in some aqueous carbohydrate solutions, Carbohyd. Res., 328, 561-572, doi:10.1016/s0008-6215(00)00141-5, 2000.

Renbaum-Wolff, L., Grayson, J. W., Bateman, A. P., Kuwata, M., Sellier, M., Murray, B. J., Shilling, J. E., Martin, S. T., and Bertram, A. K.: Viscosity of $\alpha$-pinene secondary organic material and implications for particle growth and reactivity, P. Natl. Acad. Sci. USA, 110, 8014-8019, doi:10.1073/pnas.1219548110, 2013.

Roberts, C. J. and Debenedetti, P. G.: Structure and dynamics in concentrated, amorphous carbohydrate-water systems by molecular dynamics simulation, J. Phys. Chem. B, 103, 7308-7318, doi:10.1021/jp9911548, 1999.

Roth, C. M., Goss, K.-U., and Schwarzenbach, R. P.: Sorption of a diverse set of organic vapors to urban aerosols, Environ. Sci. Technol., 39, 6638-6643, doi:10.1021/es0503837, 2005.

Saleh, R., Shihadeh, A., and Khlystov, A.: On transport phenomena and equilibration time scales in thermodenuders, Atmos. Meas. Tech., 4, 571-581, doi:10.5194/amt-4-571-2011, 2011.

Saleh, R., Donahue, N. M., and Robinson, A. L.: Time scales for gas-particle partitioning equilibration of secondary organic aerosol formed from alpha-pinene ozonolysis, Environ. Sci. Technol., 47, 5588-5594, doi:10.1021/es400078d, 2013.

Saukko, E., Lambe, A. T., Massoli, P., Koop, T., Wright, J. P., Croasdale, D. R., Pedernera, D. A., Onasch, T. B., Laaksonen, A., Davidovits, P., Worsnop, D. R., and Virtanen, A.: Humiditydependent phase state of SOA particles from biogenic and anthropogenic precursors, Atmos. Chem. Phys., 12, 7517-7529, doi:10.5194/acp-12-7517-2012, 2012. 
Seinfeld, J. H. and Pandis, S. N.: Atmospheric chemistry and physics: From air pollution to climate change, Wiley, Hoboken, NJ, 2006.

Shiraiwa, M. and Seinfeld, J. H.: Equilibration timescale of atmospheric secondary organic aerosol partitioning, Geophys. Res. Lett., 39, L24801, doi:10.1029/2012g1054008, 2012.

Shiraiwa, M., Pfrang, C., and Pöschl, U.: Kinetic multi-layer model of aerosol surface and bulk chemistry (KM-SUB): the influence of interfacial transport and bulk diffusion on the oxidation of oleic acid by ozone, Atmos. Chem. Phys., 10, 3673-3691, doi:10.5194/acp-10-3673-2010, 2010.

Shiraiwa, M., Ammann, M., Koop, T., and Pöschl, U.: Gas uptake and chemical aging of semisolid organic aerosol particles, P. Natl. Acad. Sci. USA, 108, 11003-11008, doi:10.1073/pnas.1103045108, 2011.

Shiraiwa, M., Zuend, A., Bertram, A. K., and Seinfeld, J. H.: Gasparticle partitioning of atmospheric aerosols: Interplay of physical state, non-ideal mixing and morphology, Phys. Chem. Chem. Phys., 15, 11441-11453, doi:10.1039/c3cp51595h, 2013.

Svishchev, I. M. and Kusalik, P. G.: Dynamics in liquid water, water-d2, and water-t2: A comparative simulation study, J. Phys. Chem., 98, 728-733, doi:10.1021/j100054a002, 1994.

Tong, H.-J., Reid, J. P., Bones, D. L., Luo, B. P., and Krieger, U. K.: Measurements of the timescales for the mass transfer of water in glassy aerosol at low relative humidity and ambient temperature, Atmos. Chem. Phys., 11, 4739-4754, doi:10.5194/acp-11-47392011, 2011.

Vaden, T. D., Imre, D., Beranek, J., Shrivastava, M., and Zelenyuk, A.: Evaporation kinetics and phase of laboratory and ambient secondary organic aerosol, P. Natl. Acad. Sci. USA, 108, 21902195, doi:10.1073/pnas.1013391108, 2011.

Virtanen, A., Joutsensaari, J., Koop, T., Kannosto, J., Yli-Pirila, P., Leskinen, J., Makela, J. M., Holopainen, J. K., Poschl, U., Kulmala, M., Worsnop, D. R., and Laaksonen, A.: An amorphous solid state of biogenic secondary organic aerosol particles, Nature, 467, 824-827, doi:10.1038/nature09455, 2010.

Wagner, R., Möhler, O., Saathoff, H., Schnaiter, M., Skrotzki, J., Leisner, T., Wilson, T. W., Malkin, T. L., and Murray, B. J.: Ice cloud processing of ultra-viscous/glassy aerosol particles leads to enhanced ice nucleation ability, Atmos. Chem. Phys., 12, 85898610, doi:10.5194/acp-12-8589-2012, 2012.

Wang, B., Lambe, A. T., Massoli, P., Onasch, T. B., Davidovits, P., Worsnop, D. R., and Knopf, D. A.: The deposition ice nucleation and immersion freezing potential of amorphous secondary organic aerosol: Pathways for ice and mixed-phase cloud formation, J. Geophys. Res., 117, D16209, doi:10.1029/2012jd018063, 2012.
Wang, F., Zhang, Y.-H., Li, S.-H., Wang, L.-Y., and Zhao, L.-J.: A strategy for single supersaturated droplet analysis: Confocal raman investigations on the complicated hygroscopic properties of individual mgso4 droplets on the quartz substrate, Anal. Chem., 77, 7148-7155, doi:10.1021/ac050938g, 2005.

Wilson, T. W., Murray, B. J., Wagner, R., Möhler, O., Saathoff, H., Schnaiter, M., Skrotzki, J., Price, H. C., Malkin, T. L., Dobbie, S., and Al-Jumur, S. M. R. K.: Glassy aerosols with a range of compositions nucleate ice heterogeneously at cirrus temperatures, Atmos. Chem. Phys., 12, 8611-8632, doi:10.5194/acp-128611-2012, 2012.

Zardini, A. A., Sjogren, S., Marcolli, C., Krieger, U. K., Gysel, M., Weingartner, E., Baltensperger, U., and Peter, T.: A combined particle trap/HTDMA hygroscopicity study of mixed inorganic/organic aerosol particles, Atmos. Chem. Phys., 8, 55895601, doi:10.5194/acp-8-5589-2008, 2008.

Zhang, X., Pandis, S. N., and Seinfeld, J. H.: Diffusion-limited versus quasi-equilibrium aerosol growth, Aerosol Sci. Tech., 46, 874-885, doi:10.1080/02786826.2012.679344, 2012.

Zhao, L.-J., Zhang, Y.-H., Wei, Z.-F., Cheng, H., and Li, X.H.: Magnesium sulfate aerosols studied by ftir spectroscopy: Hygroscopic properties, supersaturated structures, and implications for seawater aerosols, J. Phys. Chem. A, 110, 951-958, doi:10.1021/jp055291i, 2006.

Zhang, Y.-H. and Chan, C. K.: Study of contact ion pairs of supersaturated magnesium sulfate solutions using raman scattering of levitated single droplets, J. Phys. Chem. A, 104, 9191-9196, doi:10.1021/jp0013659, 2000.

Zhu, L., Cai, T., Huang, J., Stringfellow, T. C., Wall, M., and Yu, L.: Water self-diffusion in glassy and liquid maltose measured by raman microscopy and nmr, J. Phys. Chem. B, 115, 5849-5855, doi:10.1021/jp202663r, 2011.

Zobrist, B., Marcolli, C., Pedernera, D. A., and Koop, T.: Do atmospheric aerosols form glasses?, Atmos. Chem. Phys., 8, 52215244, doi:10.5194/acp-8-5221-2008, 2008.

Zobrist, B., Soonsin, V., Luo, B. P., Krieger, U. K., Marcolli, C., Peter, T., and Koop, T.: Ultra-slow water diffusion in aqueous sucrose glasses, Phys. Chem. Chem. Phys., 13, 3514, doi:10.1039/C0CP01273D, 2011. 